\title{
Effects of aboveground grazing on coupling among nitrifier activity, abundance and community structure
}

\author{
Xavier Le Roux ${ }^{1}$, Franck Poly ${ }^{1}$, Pauline Currey ${ }^{1,5}$, Claire Commeaux ${ }^{1}$, Brigitte Hai $^{2}$, \\ Graeme W Nicol ${ }^{3}$, James I Prosser ${ }^{3}$, Michael Schloter ${ }^{2}$, Eléonore Attard ${ }^{1}$ \\ and Katja Klumpp ${ }^{4}$ \\ ${ }^{1}$ INRA, CNRS, Université de Lyon, Université Lyon 1, UMR 5557 Ecologie Microbienne, Villeurbanne, France; \\ ${ }^{2}$ GSF National Research Center for Environment and Health, Institute of Soil Ecology, Neuherberg, Germany; \\ ${ }^{3}$ School of Biological Sciences, University of Aberdeen, Aberdeen, UK and ${ }^{4}$ Unité d'Agronomie INRA, \\ Clermont Ferrand, France
}

\begin{abstract}
The influence of switches in grassland management to or from grazing on the dynamics of nitrifier activity, as well as the abundance of ammonia-oxidizing bacteria, AOB and ammonia-oxidizing archeae, AOA, was analyzed for two years after changing management. Additionally community structure of $A O B$ was surveyed. Four treatments were compared in mesocosms: grazing on previously grazed grassland (G-G); no grazing on ungrazed grassland (U-U); grazing on ungrazed grassland $(U-G)$ and cessation of grazing on grazed grassland $(G-U)$. Nitrifier activity and abundance were always higher for G-G than U-U treatments and AOB community structure differed between these treatments. AOA abundance was in the same range as $A O B$ abundance and followed the same trend. Grazing led to a change in AOB community structure within $<5$ months and a subsequent (5-12 months) increase in nitrifier activity and abundance. In contrast, cessation of grazing led to a decrease in nitrifier activity and abundance within $<5$ months and to a later (5-12 months) change in AOB community structure. Activity in G-U and U-G was similar to that in U-U and G-G, respectively, after 12 months. Sequence analysis of 16S rRNA gene clones showed that AOB retrieved from soils fell within the Nitrosospira lineage and percentages of $A O B$ related to known Nitrosospira groups were affected by grazing. These results demonstrate that $\mathrm{AOB}$ and $\mathrm{AOA}$ respond quickly to changes in management. The selection of nitrifiers adapted to novel environmental conditions was a prerequisite for nitrification enhancement in U-G, whereas nitrification decrease in G-U was likely due to a partial starvation and decrease in the abundance of nitrifiers initially present. The results also suggest that taxonomic affiliation does not fully infer functional traits of AOB.

The ISME Journal (2008) 2, 221-232; doi:10.1038/ismej.2007.109; published online 29 November 2007

Subject Category: microbial ecology and functional diversity of natural habitats

Keywords: ammonia oxidizers; ammonia-oxidizing bacteria; ammonia-oxidizing archeae; herbivory; microbial diversity-functioning relationship; nitrogen cycle
\end{abstract}

\section{Introduction}

In grasslands, soil $\mathrm{N}$ cycling can be promoted by aboveground grazing pressure (Ruess, 1986; McNaughton et al., 1988; Frank and Groffman, 1998; Bardgett and Wardle, 2003). Negative effects can also be observed in nutrient-poor systems or under high grazing pressure (Bardgett and Wardle,

Correspondence: X Le Roux, INRA, CNRS, Université de Lyon, Université Lyon 1, UMR 5557 Ecologie Microbienne, USC 1193, bat G Mendel, 43 boulevard du 11 novembre 1918, Villeurbanne 69622, France.

E-mail: leroux@biomserv.univ-lyon1.fr

${ }^{5}$ Current address: Macaulay Land Use Research Institute, Craigiebuckler, Aberdeen AB15 8QH, UK.

Received 7 August 2007; revised 29 October 2007; accepted 29 October 2007; published online 29 November 2007
2003). Because $\mathrm{N}$ is the limiting factor for primary production in many ecosystems (Vitousek and Howarth, 1991), grazing-induced enhancement of soil $\mathrm{N}$ dynamics is a key mechanism through which herbivores can influence plant productivity in such a way as to alleviate nutritional deficiencies (McNaughton et al., 1997; Leriche et al., 2001). In particular, the regulation of nitrification has often been regarded as the key for an efficient nitrogen cycling in this context, as in contrast to most other steps in nitrogen turnover only a limited number of microbes is able to convert ammonia into nitrate. Enhanced nitrification in response to grazing pressure has been reported in different unfertilized grassland ecosystems (Groffman et al., 1993; Frank et al., 2000; Le Roux et al., 2003; Patra et al., 2005). These changes can be explained by factors such as 
urine and dung input by herbivores (Ruess and McNaughton, 1987; Petersen et al., 2004) and changes in competition for $\mathrm{N}$ between microorganisms and plants (Busso et al., 2001; Hamilton and Frank, 2001). It has been further shown that grazinginduced differences in nitrification levels in grasslands are associated with changes in the abundance and community structure of ammonia-oxidizing bacteria (AOB) that were thought to be the key players of the first step of nitrification: oxidation of ammonia into nitrite (Patra et al., 2005, 2006). This picture has changed a little in the last years, as it could be shown that ammonia oxidation can be performed not only by AOB but also by ammoniaoxidizing archaeae (AOA) that could be detected in soil (Leininger et al., 2006). However, the role of the latter group in soil $\mathrm{N}$ dynamics is still unclear, as factors influencing $\mathrm{AOA}$ and $\mathrm{AOB}$ abundance and activity are still missing.

Previous field studies have evaluated long-term (years to decades) effects of different grazing regimes on the nitrifier community, often assuming that it had reached a near-equilibrium state determined by the grazing regime. This traditional assumption of near-equilibrium conditions is often divorced from reality, because demographic and socio-economic constraints can lead to management intensification, de-intensification or abandonment in grazed grasslands at timescales much shorter than decades. Studies are thus needed to analyze the kinetics of the response of soil nitrifiers following changes in grazing regime. Such studies could provide insights into the coupling between grazing-induced changes in nitrification and concurrent changes in nitrifier abundance and community structure.

The objectives of this study and associated assumptions were:

(1) to compare the speed and extent of changes in the activity, abundance and community structure of nitrifiers for two years after switches in grassland management to or from grazing, testing the hypothesis that disturbance of a previously undisturbed system would lead to a faster response than cessation of disturbance of a previously disturbed system;

(2) to assess the ability of changes in the community structure and abundance of nitrifiers to explain observed changes in nitrification under these two scenarios, in particular whether changes in nitrification levels first required changes in nitrifier community structure as suggested by Webster et al. (2005) and

(3) to evaluate the relative importance of past and current grazing regimes on the activity, abundance and community structure of nitrifiers two years after a change in grazing regime.

Two levels of management intensity, no grazing and intensive grazing, were investigated in mesocosms initially derived from grazed and un- grazed grasslands. Four treatments were compared: (i) grazing applied on previously grazed grassland, (ii) no grazing on previously ungrazed grassland, (iii) application of grazing on previously ungrazed grassland and (iv) cessation of grazing on previously grazed grassland. The abundance of AOB and AOA, and the community structure of AOB were surveyed over 2 years. In addition, the dominant AOB phylotypes in the four treatments after 18 months were characterized by cloning and sequencing. Mechanisms explaining the observed kinetics of changes in activity, abundance and community structure of nitrifiers under the grazing application and grazing cessation scenarios are discussed according to current knowledge of nitrifier ecology.

\section{Materials and methods}

\section{Experimental design}

In May 2002, grassland monoliths (that is intact soil and plant cover) were sampled from a seminatural grassland located at Theix (France; $3^{\circ} 1^{\prime} \mathrm{E}, 45^{\circ} 43^{\prime} \mathrm{N}$ ). This grassland had been subjected, in a randomized block design, to two contrasted sheep grazing/ mowing regimes without inorganic fertilization from 1988 to 2003. Half of the plots had experienced intensive grazing/mowing (four grazing events and one cut per year), while half had experienced light grazing by sheep (one event per year). Basic soil characteristics (including texture and $\mathrm{pH}$ ) and climate were the same between both plots (Le Roux et al., 2003). Excavated monoliths (104 monoliths; 52 for each plot, size $50 \mathrm{~cm} \times 50 \mathrm{~cm}, 40 \mathrm{~cm}$ deep) were placed in five-sided stainless steel boxes with drainage holes at the bottom. Two simulated grazing regimes were then applied to these grassland mesocosms for 1 year before beginning the experiment (Appendix 1 in Supplementary information), either no grazing (ungrazed U treatment) or grazing (G treatment), which consisted of plant clipping to $5 \mathrm{~cm}$ above the soil surface and application of synthetic sheep urine five times per year to mesocosms derived from the intensively managed plot. Urine was prepared as described by Doak (1952), with a total $\mathrm{N}$ content of $0.7 \mathrm{~g} \mathrm{~N} \mathrm{I}^{-1}$, including urea $\left(1.12 \mathrm{gl}^{-1}\right)$, hippuric acid $\left(0.42 \mathrm{gl}^{-1}\right)$, allantoin $\left(0.18 \mathrm{gl}^{-1}\right)$ and creatinine $\left(0.09 \mathrm{gl}^{-1}\right)$ and with $\mathrm{pH}$ adjusted to 7 with $\mathrm{NaOH}$. For each simulated grazing event, urine was applied uniformly to the soil surface and at a level chosen such that $\mathrm{N}$ as urine represented $80 \%$ of $\mathrm{N}$ exported by clipped plant material, which is typical of the $\mathrm{N}$ budget in these grazed grasslands under field conditions. Soil moisture was monitored and kept around 35-40\% (ca. $70 \%$ of water holding capacity). After 1 year, that is in late April 2003, eight mesocosms (four grazed and four ungrazed) were sacrificed at the start of the experiment. At the same date, grazing regime was reversed for half of the remaining mesocosms (that is 24 grazed mesocosms were 
submitted to a reversion of grazing regime, from grazing to no grazing treatment, G-U; and 24 ungrazed mesocosms were submitted to the reciprocal change from no grazing to grazing treatment, U-G). Grazing regime was left unchanged for the 48 remaining mesocosms (that is 24 grazed controls, G-G; and 24 ungrazed controls, U-U). Details on the frequency of simulated grazing events in each treatment are provided in Appendix 1 in Supplementary information.

\section{Soil sampling}

Soil was sampled before reversion of grazing regime (April 2003) and after 1.5 (June 2003), 4.5 (September 2003), 12 (April 2004), 18 (September 2004) and 24 months (April 2005). Soil was sampled at least 1 month after the last simulated grazing event (Appendix 1 in Supplementary information). At each sampling date, four mesocosms per treatment (four G-G and four U-U in April 2003, and then four G-G, four U-U, four G-U and four U-G at each date) were destructively sampled. The $0-10 \mathrm{~cm}$ soil layer was sampled on a $10 \mathrm{~cm} \times 40 \mathrm{~cm}$ area in the inner part of each mesocosm and sieved ( $2 \mathrm{~mm}$ mesh size). A 50-g subsample was used for measurement of nitrifier activity and a subsample was stored at $-18^{\circ} \mathrm{C}$ for molecular analysis.

\section{Determination of nitrifier activity}

Nitrifier activity was measured according to the method proposed by Lensi et al. (1986), in which soil nitrate is measured before and after soil incubation by conversion to $\mathrm{N}_{2} \mathrm{O}$ by denitrification. We have previously shown for this soil that this approach to measure nitrate accumulation gives similar results than traditional extraction-colorimetry method but with a higher sensitivity (S Wertz and X Le Roux, unpublished). For each fresh soil sample, two subsamples (equivalent to $10 \mathrm{~g}$ ovendried soil) were placed in $150 \mathrm{ml}$ plasma flasks. One subsample was used to estimate initial soil nitrate content. The atmosphere of this flask was replaced by a 90:10 $\mathrm{He}-\mathrm{C}_{2} \mathrm{H}_{2}$ mixture and was supplied with a suspension of the denitrifying organism Pseudomonas fluorescens $\left(\mathrm{OD}_{580 \mathrm{~nm}}=2\right)$ in a solution containing water, glucose and glutamic acid (each at $1 \mathrm{mg} \mathrm{Cg}^{-1}$ dry soil). $\mathrm{N}_{2} \mathrm{O}$ accumulation was surveyed until $\mathrm{NO}_{3}^{-}$was fully converted to $\mathrm{N}_{2} \mathrm{O}$. The other subsample was used to determine $\mathrm{NO}_{3}^{-}$accumulation after addition of a solution containing water and $\left(\mathrm{NH}_{4}\right)_{2} \mathrm{SO}_{4}\left(200 \mu \mathrm{g} \mathrm{N} \mathrm{g}{ }^{-1}\right.$ dry soil) to obtain $80 \%$ of the water holding capacity. The flask was sealed with parafilm and incubated aerobically at $28^{\circ} \mathrm{C}$. After incubation for $7 \mathrm{~h}$, the soil subsample was enriched with $P$. fluorescens and incubated as described above to convert nitrate fully to $\mathrm{N}_{2} \mathrm{O}$. During methodological tests, nitrification rate was found to be constant during the first $7 \mathrm{~h}$ for this soil. $\mathrm{N}_{2} \mathrm{O}$ was analyzed on a Varian STAR 3400 gas chromatograph. Nitrifying activity $\left(\mu \mathrm{g} \mathrm{h}^{-1} \mathrm{~g}^{-1}\right.$ dry soil) was computed by subtracting the nitrate content initially present in the soil from that present after incubation.

\section{Quantification of $A O B$ and $A O A$ abundances}

The abundance of $\beta$-proteobacterial $\mathrm{AOB}$, that is representing known AOB in soil, was measured by quantitative PCR (qPCR) targeting 16S rRNA gene sequences specific for this group (Hermansson and Lindgren, 2001). The final reaction volume was $25 \mu \mathrm{l}$, with iQSupermix (Bio-Rad), $1 \mu \mathrm{M}$ of a 2:1 ratio of primer CTO189fA/B and CTO189fC, $1 \mu \mathrm{M}$ of RT1r primer, $0.5 \mu \mathrm{M}$ of TPM1probe, $0.4 \mathrm{mg} \mathrm{ml}^{-1}$ bovine serum albumin (BSA), $10 \mathrm{ng}$ of sample DNA or $5.72 \times 10^{8}-5.72 \times 10^{2}$ copies of the standard DNA (purified AOB 16S rRNA gene PCR product of ATCC19718 Nitrosomonas europaea). The samples were run twice on Opticon2 (MJ Research, Waltham, MA, USA) as follows: $3 \mathrm{~min}$ at $95^{\circ} \mathrm{C}, 45$ cycles at $95{ }^{\circ} \mathrm{C}$ for $15 \mathrm{~s}$ and $58^{\circ} \mathrm{C}$ for $1 \mathrm{~min}$, and $8 \mathrm{~min}$ at $56^{\circ} \mathrm{C}$. No treatment effect was observed on amplification efficiency. To control possible PCR inhibition by material from environmental samples, each standard concentration was co-amplified with several dilutions of pooled samples, but no inhibition was observed.

The abundance of AOA was measured by qPCR targeting arachaeal amoA gene. Fragments (624 bp) were obtained using the primer set $19 \mathrm{~F}$ (Leininger et al., 2006) and CrenamoA616r48x (5'-gccatccabckr tangtcca- $3^{\prime}$ ), which was designed on the basis of all available soil-derived AOA amoA sequences in GenBank in November 2006 (S Leininger, personal communication). Each $25 \mu \mathrm{l}$ reaction mixture contained $0.06 \%$ BSA (Sigma-Aldrich, St Louis, MO, USA), 5 pmol of each primer (Metabion, Bayern, Germany), $\times 1$ Power SYBR Green PCR Master Mix (Applied Biosystems, Foster City, CA, USA) and $2 \mu \mathrm{l}$ of DNA template or standard, respectively. The PCR reactions were carried out on the ABI Prism 7300 Cycler (Applied Biosystems) performing an initial enzyme activation at $95^{\circ} \mathrm{C}$ for $10 \mathrm{~min}$, followed by 40 cycles at $94{ }^{\circ} \mathrm{C}$ for $45 \mathrm{~s}, 50^{\circ} \mathrm{C}$ for $45 \mathrm{~s}$ and $72^{\circ} \mathrm{C}$ for $45 \mathrm{~s}$. As standard, a serial dilution of the crenarchaeal fosmid clone 54d9, described in Treusch et al. (2005), was used. Melting curve analysis confirmed the specificity of the amplification, whereas amplification efficiencies of $82-89 \%$ were obtained. Possible inhibitory effects of co-extracted humic compounds in soil extracts were checked by dilution series, but no inhibition was observed.

\section{Characterization of the structure of the $A O B$ community}

For each sample, DNA was extracted from $0.5 \mathrm{~g}$ sieved and frozen soil using the FastDNA SPIN Kit for Soil (BIO 101 Systems; Qbiogene, Carlsbad, CA, USA) yielding approximately $6 \mu \mathrm{gNA} \mathrm{g}^{-1}$ soil. The 
AOB community structure was characterized at five of the six sampling dates: 0, 4.5, 12, 18 and 24 months (that is 72 samples), and was analyzed by PCR-denaturing gradient gel electrophoresis (DGGE). Amplification of $16 \mathrm{~S}$ rRNA gene fragments from extracted soil DNA was achieved by primary amplification with CTO189f and CTO654r primers (Kowalchuk et al., 1997) that are specific for the majority of $\beta$-proteobacterial $\mathrm{AOB}$, and with a secondary nested amplification using bacterial 357f-GC and 518r primers (Muyzer et al., 1993). CTO and bacterial primers amplified 465- and 161-bp fragments, respectively. PCR was carried out in 20 and $50 \mu \mathrm{l}$ reaction volumes for primary and secondary amplifications, respectively, with a Biometra thermal cycler (Goettingen, Germany). The reaction mixture contained $8 \mathrm{ng}$ of template DNA, 0.2 and $0.1 \mu \mathrm{M}$ of each primer for the first and second PCR, respectively, $1 \times$ PCR buffer (Bioline, London, UK), $250 \mu \mathrm{M}$ deoxynucleoside triphosphate, $1.5 \mathrm{mM} \mathrm{MgCl}_{2}, 20 \mathrm{ng}$

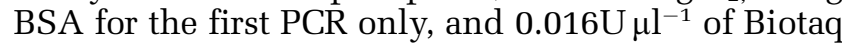
DNA polymerase (Bioline). The thermocycling conditions were modified from Freitag and Prosser (2003): 28 cycles instead of 35 for the second PCR and a final elongation time of $10 \mathrm{~min}$ for each PCR. The PCR products were examined by electrophoresis on $2 \%$ agarose gels (Invitrogen, Cergy Pontoise, France) stained with ethidium bromide. DGGE analysis of PCR products was carried out using the D-Code Universal Mutation Detection System (BioRad Laboratories, Hercules, CA, USA) with $8 \%$ polyacrylamide gels containing a gradient of 30-60\% denaturant, prepared using a gradient maker (Roth, Karlsruhe, Germany), 100\% denaturing solution being defined as $7 \mathrm{M}$ urea and $40 \%$ formamide. Gels were run for $16 \mathrm{~h}$ at $75 \mathrm{~V}$ in $1 \times$ Tris acetate EDTA (TAE) buffer at $60^{\circ} \mathrm{C}$. Following electrophoresis, gels were silver stained and photographed with a digital camera (Sony DSC-F77).

\section{Characterization of major AOB phylotypes by}

cloning-sequencing

The major AOB phylotypes present in each treatment 18 months after the change in grazing regime were determined by cloning and sequencing. Clone libraries were generated from PCR products obtained by amplification with CTO189f and CTO654r primers from all the soils sampled after 18 months, that is four replicate monoliths for each of the four treatments. Cloning was carried out using the pGEM T-Easy vector system (Promega Ltd, Southampton, UK) and JM109 supercompetent Escherichia coli cells (Stratagene Inc., Maidstone, UK) and 26-27 clones, randomly selected from each per soil sample (total of 418 clones), were sequenced (Genome Express, Meylan, France).

Sequences were aligned with partial AOB $16 \mathrm{~S}$ rRNA gene sequences previously published and used to define phylogenetic groups (Appendix 2 in Supplementary information) using Muscle align- ment of SeaView software (Galtier et al., 1996). Phylogenetic analysis was performed using three treeing methods: (i) parsimony method, (ii) neighbor joining method with Jukes and Cantor model of substitution and (iii) maximum likelihood tree, using four categories of substitutions with an estimated gamma distribution parameter and JC69 model of substitution. The first two methods were performed with Phylowin software (http://pbil. univ-lyon1.fr/software/phylowin.html) (Galtier et al., 1996), while the third method was performed with Phyml software (http://atgc.lirmm.fr/phyml/) (Guindon and Gascuel, 2003). Then a consensus tree was computed with Consense in the PHYLIP package 3.66 (http://evolution.genetics.washington. edu/phylip.html). The consensus tree was visualized using NJ plot (http://pbil.univ-lyon1.fr/soft ware/njplot.html) (Perriere and Gouy, 1996)). For each monolith, the percentage of AOB phylotypes belonging to the main AOB phylogenetic clusters identified in the literature (Stephen et al., 1996; Purkhold et al., 2000; Koops and Pommerening-Röser, 2001; Kowalchuk and Stephen, 2001; Wagner et al., 2002) was determined. Sequences obtained in this study have been deposited in the GenBank database (Appendix 2 in Supplementary information).

\section{Data analysis}

Two-factor analysis of variance was performed to determine the effects of grazing treatment, time and grazing $\times$ time interaction on the activity and abundance of nitrifiers. For each variable, Duncan's and Fisher's tests were then used to determine if means differed significantly between treatments at each date. The effect of grazing treatment on the percentage of AOB phylotypes related to previously defined AOB phylogenetic groups was also tested using Duncan's and Fisher's tests.

To analyze genetic fingerprints, the intensity and relative position of each DNA band in all lanes were determined according to a reference lane using GelCompar software (Applied Maths, Kortrijk, Belgium). The total band intensity for each lane was normalized among lanes, and data were square roottransformed. Bacterial community matrices were analyzed using PRIMER software (version 2, PRIMER-E Ltd, Plymouth, UK). For each date, ANOSIM (one-way analysis of similarities) was performed to compare community structure among each pair of treatments, and the SIMPER (SIMilarity PERcentages) procedure was used to compute the percentage of dissimilarity between community structure for each pair of treatments. Changes in AOB community structure after reversion of grazing regime were quantified by determining the percentage dissimilarity of community structure between (i) soils that had experienced reversion of grazing regime and (ii) control soils under the past grazing regime (that is $\mathrm{U}-\mathrm{G}$ vs $\mathrm{U}-\mathrm{U}$, and $\mathrm{G}-\mathrm{U}$ vs $\mathrm{G}-\mathrm{G}$ ). A similar approach was adopted to determine the 
effect of the new grazing regime on the structure of the AOB community.

\section{Results}

Changes in nitrifier activity

The effects of grazing, time and grazing $\times$ time interaction on nitrifier activity were all significant $(P \leqslant 0.001)$. Activity was always higher for G-G than U-U treatments, except 1.5 months after change in grazing regime when variance for activity values was high for G-G and G-U treatments (Figure 1). Cessation of grazing led to a rapid decrease in nitrifier activity as compared to G-G treatment (detected as soon as 4.5 months), and activity for G-U treatment became similar to that for U-U treatment after 12-18 months (Figure 1). Application of grazing did not lead to any change in nitrifier activity during the first 5 months (no change between U-G and U-U treatments). Activity then strongly increased for the U-G treatment as compared to the U-U treatment and became similar to that for the G-G treatment within $\leqslant 12$ months (Figure 1).

Changes in the abundance of $A O B$ and $A O A$

The effects of grazing and time on the abundance of AOB were significant $(P=0.0001$ and 0.0005, respectively), whereas the effect of grazing $\times$ time interaction was not. The abundance of AOB always tended to be higher for G-G than U-U treatments. However, due to the high variance of abundance data (Figure 2) this was significant only for 4.5, 12 and 18 months after the change in grazing regime. Cessation of grazing led to a rapid decrease in AOB abundance as compared to G-G treatment, and AOB abundance for G-U treatment became similar to that for U-U treatment within 12-18 months (Figure 2).

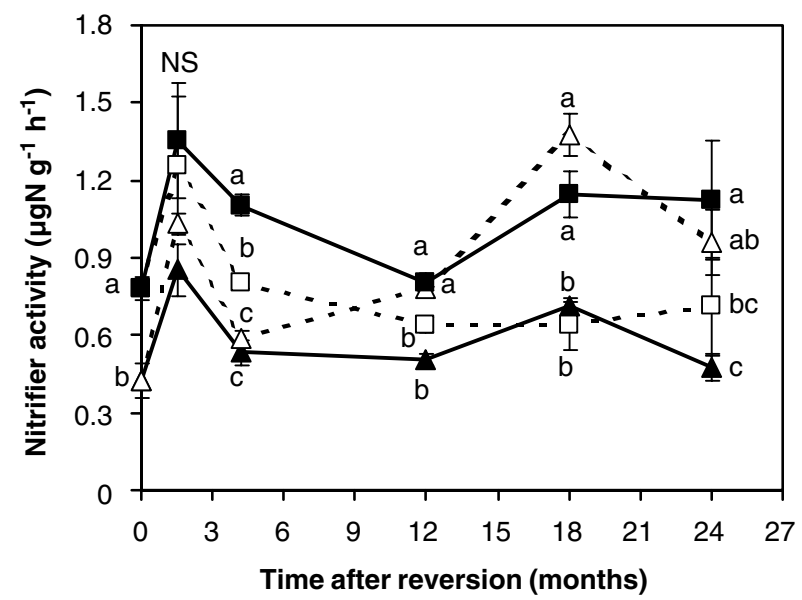

Figure 1 Temporal changes in nitrifier activity in grassland mesocosms subjected to different grazing treatments: ( $\boldsymbol{\square}$ ) grazed controls, G-G; $(\mathbf{\Delta})$ ungrazed controls, U-U; $(\square)$ reversion from grazed to ungrazed, G-U and $(\Delta)$ reversion from ungrazed to grazed, U-G. Bars are standard errors $(n=4)$. Values with different letters differ significantly with $P<0.05$.
Application of grazing led to an increase in AOB abundance as compared to U-U treatment, although this increase was not significant due to large variance in abundance values (Figure 2).

Abundances of AOA and AOB were in the same order of magnitude (Figure 2), and the abundance of AOA was significantly and linearly related to that of AOB $\left(y=0.75 x+0.798\right.$ in $10^{6}$ copies $\left.g^{-1} ; R^{2}=0.35\right)$. Interestingly, dynamics of AOA gene copy numbers were similar to the AOB abundance dynamics described above (Figure 2). Again, cessation of grazing tended to decrease AOA abundance as compared to G-G treatment after 12 months, whereas application of grazing resulted in an increase of AOA abundance as compared to U-U treatment after 12 months (Figure 2). A tendency for higher abundance of AOA in G-G than U-U treatments was observed, but this was significant only 1.5 and 4.5 months after the change in grazing regime $(P=0.06$ at day 0$)$, probably due to the high variance of abundance data (Figure 2).
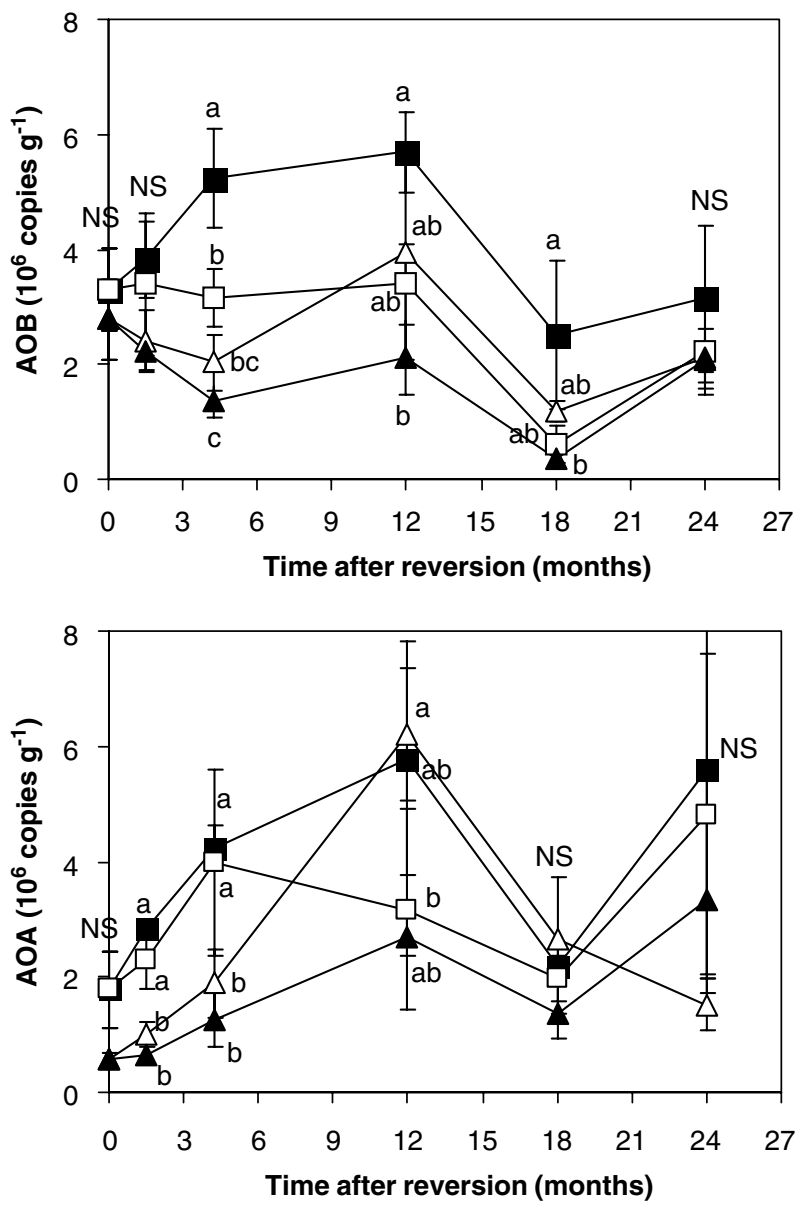

Figure 2 Temporal changes in (top) abundance of ammoniaoxidizing bacteria (AOB) and (bottom) abundance of ammoniaoxidizing archeae (AOA), in mesocosms subjected to different grazing treatments. Symbols as in Figure 1. Bars are standard errors $(n=4)$. Values with different letters differ significantly with $P<0.05$. 
All data were calculated on the basis of grams of soil. However, the results did not change significantly if the values were based on nanograms
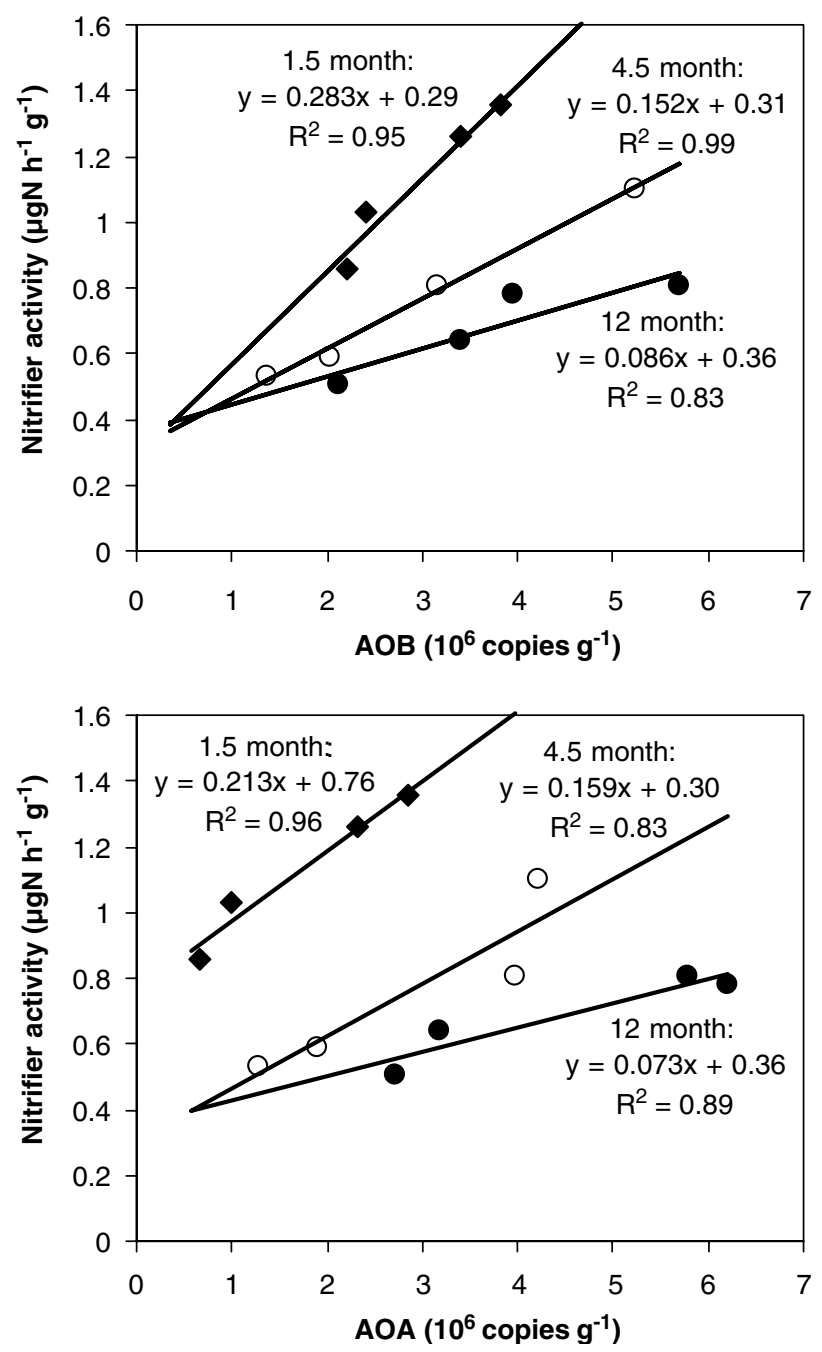

Figure 3 Correlations between nitrifier activity and (top) ammonia-oxidizing bacteria (AOB) abundance and (bottom) ammonia-oxidizing archeae (AOA) abundance, observed 1.5 $(\diamond), 4.5(\bigcirc)$ and 12 months $(\bullet)$ after reversion of grazing regime. Each point corresponds to mean treatment values $(n=4)$. Relationships for both $\mathrm{AOB}$ and AOA were not significant at 18 and 24 months. extracted DNA (data not shown), indicating the robustness of the obtained results.

\section{Relationships between nitrifier activity and $A O B$ or AOA abundance}

Strong correlations were observed between mean treatment values of nitrifying activity and both AOB and AOA abundances 1.5, 4.5 and 12 months after the change in grazing regime (Figure 3). At the later time points, no significant correlation was observed for AOB and AOA (data not shown).

\section{Changes in $A O B$ community structure}

For each treatment, the major bands observed by DGGE analysis of amplified bacterial ammonia oxidizer 16S rRNA genes changed substantially with time (not shown), indicating dynamics of major AOB populations. However, the percentage of dissimilarity for the AOB community structures between G-G and U-U control treatments remained constant (around 50\%) over 2 years (Table 1; Figure 4). Cessation of grazing did not lead to any detectable change in AOB community structure over the first 5 months (no change between G-U and G-G treatments). However, AOB community structure was strongly modified from 12 to 24 months (Table 1 ; Figure 4). In contrast, the application of grazing led to a rapid change in $\mathrm{AOB}$ community structure (detected as soon as 4.5 months) (Table 1; Figure 4).

With increasing time after change in grazing regime, AOB community structure in treatments where grazing regime had been changed did not resemble that for control treatment corresponding to the new grazing regime, that is G-U vs U-U and U-G vs G-G (Table 1; Figure 5). The only exception was for U-G treatment at 24 months, indicating that the AOB community structure at this timescale became mainly determined by the new management regime for the grazing application scenario.

\section{Relative abundance of $A O B$ phylotypes related to} different phylogenetic groups

Of the 418 retrieved partial sequences, $95 \%$ were related to previously defined $\beta$-proteobacterial

Table 1 Results ( $P$-values) of one-way ANOSIM for comparisons of the AOB community structure assessed by DGGE profiles between the different treatments

\begin{tabular}{|c|c|c|c|c|c|}
\hline & Before reversion & 4.5 months & 12 months & 18 months & 24 months \\
\hline U-U vs G-G & 0.03 & 0.03 & 0.05 & 0.03 & 0.05 \\
\hline U-U vs U-G & - & 0.05 & 0.05 & 0.05 & 0.03 \\
\hline G-G vs G-U & - & NS & 0.05 & 0.03 & 0.03 \\
\hline U-G vs G-G & - & 0.03 & 0.03 & 0.03 & NS \\
\hline G-U vs U-U & - & 0.03 & 0.03 & 0.05 & 0.05 \\
\hline G-U vs U-G & - & 0.03 & 0.03 & 0.03 & 0.05 \\
\hline
\end{tabular}

Abbreviations: ANOSIM, analysis of similarities; AOB, ammonia-oxidizing bacteria; DGGE, denaturing gradient gel electrophoresis; G-G, grazed controls; G-U, change from grazed to ungrazed; NS, not significant; U-G, change from ungrazed to grazed; U-U, ungrazed controls. 


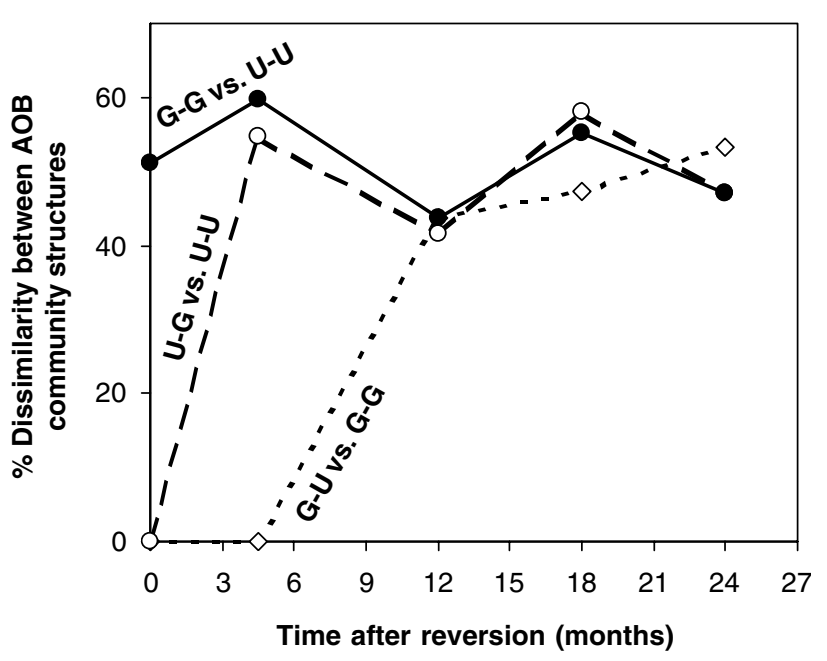

Figure 4 Percentage of dissimilarity between the structure of ammonia-oxidizing bacteria (AOB) community in mesocosms subjected to a reversion of grazing regime and in control mesocosms subjected to the initial grazing regime, that is $(O)$ U-G vs U-U, and $(\diamond)$ G-U vs G-G. Percentage of dissimilarity between the AOB community structure in the two controls $(\bullet)$ is presented for comparison.

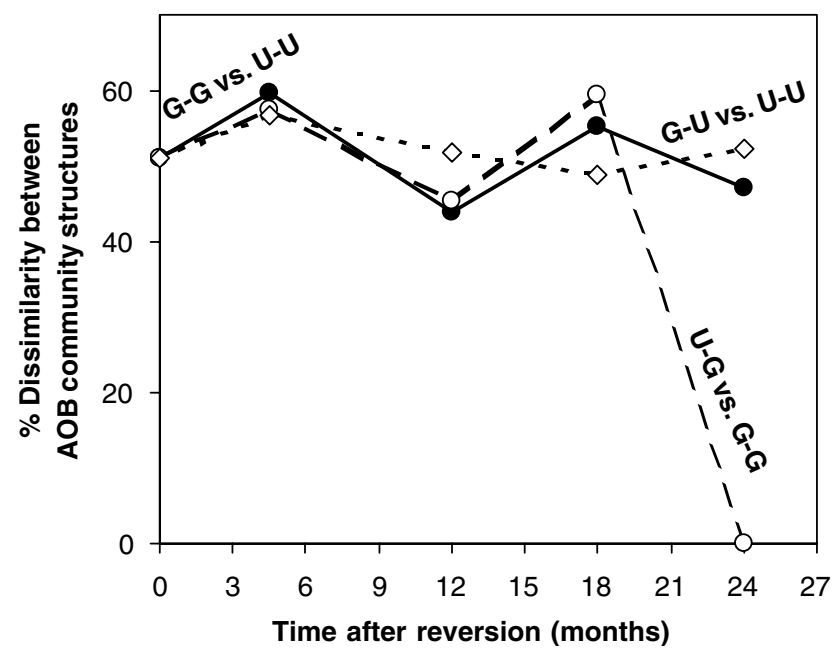

Figure 5 Percentage of dissimilarity between ammonia-oxidizing bacteria (AOB) community structure in mesocosms subjected to reversion of grazing regime and in control mesocosms subjected to the new grazing regime, that is $(O)$ U-G vs G-G, and $(\diamond)$ G-U vs U-U. Percentage of dissimilarity between the AOB community structure in the two controls $(\mathbf{O})$ is presented for comparison.

ammonia oxidizers (Appendix 3 in Supplementary information): 1 related to Nitrosomonas, and 396 to Nitrosospira. Of the 21 other sequences, 20 were affiliated to Methylophilaceae and 1 was a bacterial sequence not related to any known groups.

Of the AOB phylotypes retrieved after 18 months from G-G soils, $82 \%$ were related to Nitrosospira cluster 3a, whereas the AOB phylotypes retrieved from U-U soils were distributed in clusters $0,3 a, 3 b$ and 4 (15-39\% for each cluster) (Figure 6). Cessation of grazing led to a significant decrease in the relative abundance of AOB phylotypes related to cluster 3a (G-U as compared to G-G treatment), whereas a marginally significant increase in the relative abundance of phylotypes related to clusters 0 and 4 was observed (Figure 6). Application of grazing led to a significant decrease in the relative abundance of AOB phylotypes related to cluster $3 b$ (U-G as compared to U-U treatment), whereas a marginally significant increase in the relative abundance of phylotypes related to cluster 0 was observed.

\section{Discussion}

Differences in nitrifier activity, $A O B / A O A$ abundance and $A O B$ community structure between control grazed and ungrazed mesocosms

Nitrifier activity, AOB and AOA abundances, and AOB community structure exhibited important variations with time. Important temporal variations in nitrifying activity and abundance of AOB have already been reported in grassland and cropping systems (Berg and Rosswall, 1987). In such systems, this could be due to multiple forcings by disturbance regime, climate and plant physiology and phenology acting at a range of scales. However, the activity and abundance of nitrifiers were always higher on G-G than U-U soils and AOB community structure always differed between these treatments throughout the 24-month period studied. Previous analyses of grazing effects on AOB communities in grasslands were generally based on snapshot characterization at only one or two times (Webster et al., 2002; Patra et al., 2005). Comparison of G-G and U-U treatments show that grazing-induced enhancement of nitrifier activity and of both $\mathrm{AOB}$ and AOA abundances was remarkably conserved with time. Similarly, a high grazing-induced difference in AOB community structure was maintained between grazed and ungrazed conditions, despite changes in relative abundance of dominant AOB phylotypes for a given grazing regime with time. The data therefore indicate that, despite temporal variations, the effect of grazing on nitrifiers was remarkably stable from a functional rather than structural point of view.

Importance of changes in $A O B$ and $A O A$ abundance and $A O B$ community structure for changes in nitrification after change in grazing regime It was hypothesized that disturbance of a previously undisturbed system would lead to a faster response than suppression of disturbance on a previously disturbed system. The observed responses were actually more subtle because nitrifier activity responded even more quickly to cessation of grazing (within $<5$ months) than to application of grazing (5-12 months). The temporal changes in nitrifier activity after change in grazing regime could result from (i) changes in nitrifier abundance, (ii) changes 

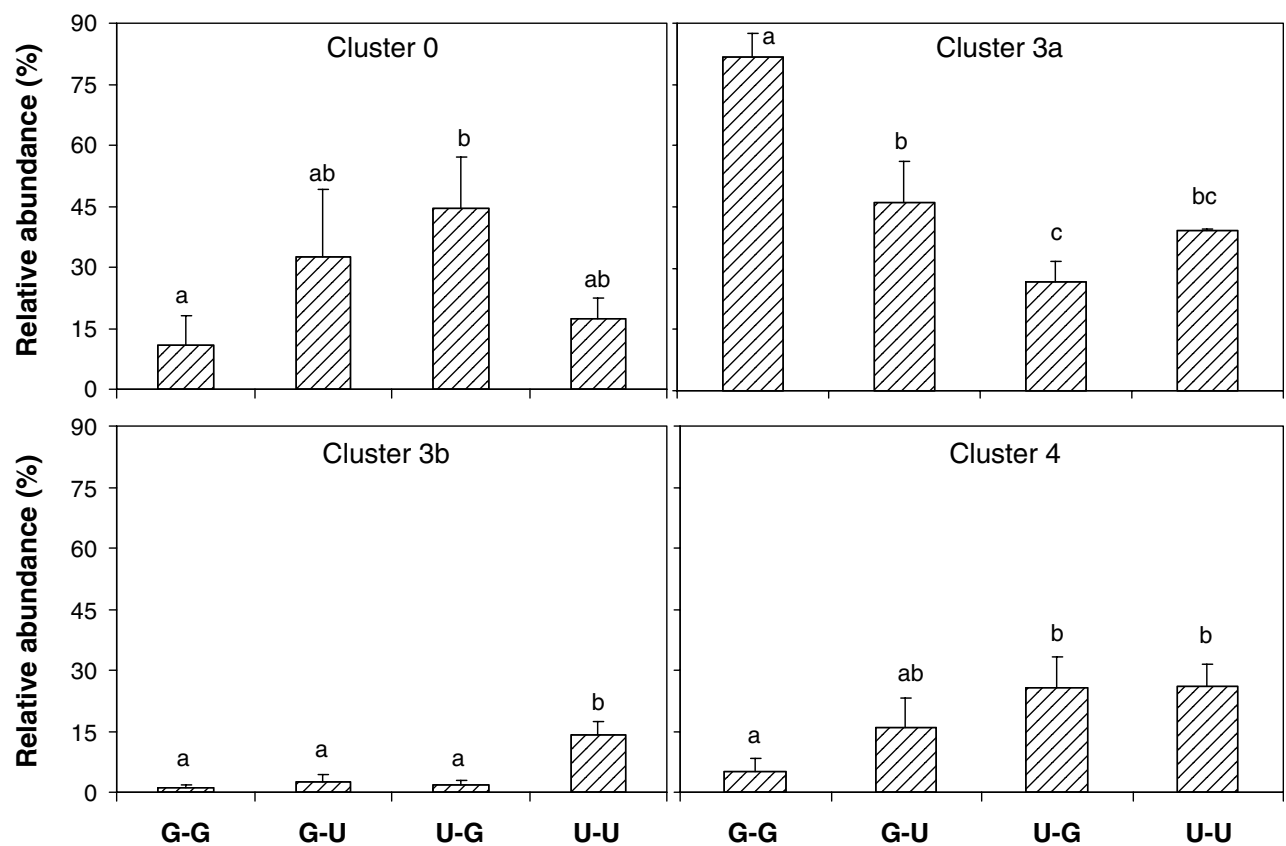

Figure 6 Relative abundances of partial ammonia-oxidizing bacteria (AOB) sequences retrieved from soils experiencing the four grazing treatments, 18 months after change in grazing regime, as related to different Nitrosospira groups defined in the literature. Relative abundance of sequences related to cluster 2 was always $<3 \%$ without significant grazing effect. Means of four replicates (mesocosms) are presented with standard errors. Values with different letters differ significantly with $P<0.05$.

in the physiological activity of individual nitrifying organisms (that is mean activity per cell) and/or (iii) changes in nitrifier community structure. AOB and AOA abundances were measured by qPCR, so that results were not influenced by cultivation biases that can be high (Kowalchuk et al., 2000; Phillips et al., 2000a, b). Because all known $\beta$-proteobacterial ammonia oxidizers are thought to carry only a single 16S rRNA gene per genome (Kowalchuk and Stephen, 2001; see also genome data available for $N$. europaea ATCC19718, N. eutropha C91 and Nitrosospira multiformis ATCC25196), the measured gene copy numbers should be close to cell numbers for AOB. Similarly, based on the existing data for AOA (Könneke et al., 2005; Treusch et al., 2005) it can be assumed that per organism only one amo $A$ copy exists. Thus, the measured AOA amoA gene copy numbers should be close to the cell numbers for AOA. For both grazing application and grazing cessation scenarios, changes in nitrifier activity were strongly correlated with changes in the abundance of both $\mathrm{AOB}$ and AOA, at least during the first 12 months. The relationship between activity and AOB abundance is consistent with the correlations obtained between nitrification levels and the abundance of cultivable $\mathrm{AOB}$ at the same study sites under field conditions (Patra et al., 2005). Similarly, strong correlations were obtained between nitrification and the abundance of $\mathrm{AOB}$ assessed by qPCR in salt marsh sediments (Dollhopf et al., 2005), among various soil depths in arable cropping systems (Berg and Rosswall, 1987), and in soil amended with or without ammonium
(Hesselsøe et al., 2001) (but see Mendum et al., 1999; Phillips et al., 2000a; Wheatley et al., 2003). Whereas some data have been available on the expected behavior of AOB, almost no results have been published so far on abundance of AOA in grassland soils and possible interaction with grazing. The data published so far has shown a higher abundance of AOA to AOB (Leininger et al., 2006; He et al., 2007). However, it has been shown in these studies that in deeper soil layers the AOA/AOB ratio increases, which may be an indication that AOA/ AOB ratio increases with increased nutrient limitation. This could explain that AOA abundance was comparable to AOB abundance in the fertile grasslands studied here. Given that transformation rates for ammonium into nitrite by AOA is currently assumed to be lower than for AOB (Könneke et al., 2005), it can be postulated that the major part of nitrification in the investigated grassland soils was related to AOB activity.

Application of grazing led first (within $<5$ months) to a change in AOB community structure, with subsequent increases in activity and abundance. The timescale for the grazing-induced change in the structure of the AOB community is consistent with conclusions of Avrahami et al. (2003) that changes in the AOB community structure can be detected a few weeks after addition of a fertilizer or urea-amended slurry. Given that particular AOB populations can be selected under high- vs lowammonia conditions (Kowalchuk and Stephen, 2001) and that urine input leads quickly to increased $\mathrm{NH}_{3}$ availability in grassland soil (Luo et al., 1999), 
changes in ammonia availability were likely the key factor explaining the observed changes in AOB community structure for U-G treatment. This is consistent with results of Patra et al. (2006) who observed that grazing-induced changes in ammonia availability explained changes in nitrifier activity and community structure at these study sites under field conditions. Furthermore, the preliminary shift in community structure observed before any change in activity is consistent with results reported by Webster et al. (2005), who observed that, in natural, ungrazed soils, a change in AOB community structure was often required before enhancement of nitrification following sheep urine application. The authors suggested that, when AOB communities were dominated by strains sensitive to high ammonia concentration, a shift toward ammonia-tolerant AOB populations was needed to allow nitrification increase. Our results show that, under more realistic conditions (that is planted grassland soils experiencing both urine addition and plant defoliation events), selection of particular nitrifying populations adapted to the new environmental conditions, in particular persistent high urea supply, was a prerequisite for nitrification enhancement in the U-G treatment. Characterization of the physiological traits of dominant AOB populations under grazing vs no grazing conditions, particularly their sensitivity to urea/ammonia levels, is thus a priority. The ability to produce urease that is not encountered in all AOB (Koops and Pommerening-Röser, 2001) could also be an important physiological attribute in this context.

In contrast, cessation of grazing led first (within $<5$ months) to a decrease in nitrifier activity and AOB abundance, and only later to a change in community structure. Similarly, Griffiths et al. (2003) reported important physiological effects of water stress on the activity of microbial community in grassland soil without any detectable effect on the structure of the microbial community. Thus, the decrease in nitrification observed early for the G-U treatment was likely due to partial starvation and decrease in the abundance of AOB initially present.

For both G-U and U-G treatments, nitrifier activity became similar to that observed for control treatments corresponding to the new grazing regime after ca. 12 months. In contrast, this was not observed for the community structure, except for U-G treatment after 24 months. This shows that similar nitrifier activity can be insured by AOB communities differing in their community structure, which is consistent with the high functional redundancy of soil bacterial communities including nitrifiers (Wertz et al., 2006, 2007). Investigating the composition of the active nitrifier community using mRNA rather than the genetic community structure could partly explain the decoupling observed between nitrifier activity and community structure.
Phylogenetic affiliation of dominant $A O B$ phylotypes according to grazing regime

We assessed AOB community structure using two methods-DGGE analysis of amplified 16S rRNA genes and quantification of clones belonging to $16 \mathrm{~S}$ rRNA-defined phylogenetic groups, following sequencing. Both approaches potentially suffer from biases associated with cell lysis, DNA extraction, choice of primers, PCR amplification and cloning, as many other molecular techniques applicable on a large number of samples, but both are accepted methods for assessment of relative abundance and community composition and the biases were probably the same for all samples here and thus did not prevent comparison of treatment effects. DGGE was used to provide a more general picture of community structure at lower cost, whereas cloning and sequencing were performed to gain greater fine-scale taxonomic resolution.

Sequencing results show that CTO primers adequately amplified fragments of the $16 \mathrm{~S}$ rRNA gene from Proteobacteria $\beta$-subgroup AOB, and only $5 \%$ of the retrieved sequences were not related to Nitrosospira or Nitrosomonas. In contrast, up to $80 \%$ of the clones retrieved from activated sludge and sediment samples with the CTO primer set fell outside AOB lineages in a previous study (Nicolaisen and Ramsing, 2002).

Nearly all AOB sequences (396 among 397) retrieved from soil of these grassland mesocosms after 18 months were affiliated to Nitrosospira. Dominance of the AOB community by Nitrosospira has already been reported for soil environments (for example, Kowalchuk et al., 2000; Wheatley et al., 2003). Although the various Nitrosopira phylogenetic clusters have been shown to sometimes yield unstable tree topologies (Head et al., 1993; Purkhold et al., 2000), the assignation of the AOB clones to particular clusters in our study was found to be reliable, that is robust when comparing the assignation obtained with the three different treeing algorithms. The only exception was cluster 2 that was differentiated from cluster $3 \mathrm{~b}$ only with the maximum likelihood method, but only eight sequences were affiliated to this 'cluster 2'. Both cessation and application of grazing strongly modified the relative abundance of AOB phylotypes as related to Nitrosospira clusters defined in the literature, whereas the distribution of AOB phylotypes among clusters for treatments corresponding to changes in grazing regime did not resemble that for control treatment corresponding to the new grazing regime. This effect of change in grazing regime and importance of both past and new grazing regimes are consistent with DGGE data for the same samples.

Several authors have reported possible links between the phylogenetic position of AOB and their ecophysiological traits. For instance, based on physiological measurements made on pure culture and enrichment culture representatives of Nitrosospira 
clusters 3a and 3b, Webster et al. (2005) suggested that AOB related to cluster 3 a could be sensitive to high ammonia concentration, while AOB related to cluster $3 \mathrm{~b}$ could be tolerant. Because (i) AOB related to cluster 3a were strongly dominant in G-G soils experiencing urine inputs, (ii) the relative abundance of AOB related to cluster $3 b$ was highest in U-U soils and (iii) the relative abundance in AOB related to cluster 0 increased in both $\mathrm{U}-\mathrm{G}$ and $\mathrm{G}-\mathrm{U}$ soils, our results suggest that AOB adapted to both high and low $\mathrm{N}$ levels exist within each of these three clusters. Similarly, Kowalchuk et al. (2000) observed a predominance of Nitrosospira cluster 4 in late successional fields, likely explained by a low ammonia availability in unfertilized grasslands. Consistently, we observed a higher relative abundance of AOB related to cluster 4 in U-U than G-G soils, and an increase in their relative abundance following cessation of grazing/urine input; however, application of grazing did not affect the relative abundance of AOB related to cluster 4 in U-G soils. All these results suggest that functional diversity of AOB as regards to N levels exists within Nitrosospira clusters and that taxonomic affiliation does not fully infer functional traits of these organisms.

Urine input: the key driver of changes in nitrification, $A O B / A O A$ abundance and $A O B$ community structure Because aboveground grazing was mimicked by plant clipping and urine addition on grassland mesocosms, the results do not reflect exactly the response of grassland soil to change in grazing regime under field conditions. Indeed, changes in dung deposition and trampling regime can also influence soil microbiota (Abdelmagid et al., 1987; Ruess and McNaughton, 1987). However, changes in urine input, root functioning and competition between plants and microorganisms are thought to be the key factors mediating linkages between grazing of aboveground plant parts and soil microbiota (Hamilton and Frank, 2001; Bardgett and Wardle, 2003). More generally, more or less severe experimental manipulation of environmental conditions, disturbance regimes and ecological systems is needed to understand better the behavior and driving factors of microbial communities (Kowalchuk and Stephen, 2001). The extent to which aboveground grazing regime was adequately mimicked can be appreciated by the fact that differences in the nitrifier activity between grazed and ungrazed control mesocosms were maintained during the two-year period studied and were consistent with values measured under field conditions (Patra et al., 2005). Furthermore, the fact that nitrifier activity and $\mathrm{AOB}$ and $\mathrm{AOA}$ abundances were determined mainly by the new management regime after 12 months for both scenarios of change in simulated grazing regime showed that urine input and/or plant clipping were the key drivers of the observed effects of grazing on nitrifiers. In addition, changes in botanical composition may explain differences in nitrifier activity, abundance and community structure between long-term grazing regime (Patra et al., 2006), but this could not explain the early changes in AOB characteristics in the present study where no major change in plant species composition was observed during the first 6 months in all mesocosms ( $\mathrm{K}$ Klumpp, personal communication).

\section{Conclusion}

These results are an important step forward to understand the influence of different management techniques on microbial communities involved in nitrification. In particular, they demonstrate that $\mathrm{AOB}$ and $\mathrm{AOA}$ respond quickly to changes in aboveground grazing regime and that, at least for AOB, the mechanisms involved differ between grazing application and grazing cessation scenarios. Selection of particular AOB populations adapted to the new environmental conditions, in particular persistent high urea supply, was a prerequisite for nitrification enhancement in the U-G treatment. In contrast, the decrease in nitrification observed early for the G-U treatment was likely due to a partial starvation and decrease in the abundance of nitrifying organisms initially present. Nitrifier activity and AOB and AOA abundances became similar to those observed in control mesocosms experiencing the new grazing regime after ca. 12 months. In contrast, both past and new management regimes influenced the AOB community structure and distribution of AOB among phylogenetic groups, which shows the extent of decoupling between community function and composition following change in grassland management regime.

\section{Acknowledgements}

This study was funded by the French Institute of Agronomic Research (INRA, projet innovant Département EA) and was also supported by the Alliance program. We thank V Degrange for comments on the manuscript and L Darmedru for help during cloning- sequencing. We deeply thank Sven Leininger and Christa Schleper from the University of Bergen/Norway for providing the unpublished new primers for AOA quantification.

\section{References}

Abdelmagid AH, Schuman GE, Hart RH. (1987). Soil bulkdensity and water infiltration as affected by grazing systems. J Range Manage 40: 307-309.

Avrahami S, Liesack W, Conrad R. (2003). Effects of temperature and fertilizer on activity and community structure of soil ammonia oxidizers. Environ Microbiol 5: 691-705. 
Bardgett RD, Wardle DA. (2003). Herbivore-mediated linkages between aboveground and belowground communities. Ecology 84: 2258-2268.

Berg P, Rosswall T. (1987). Seasonal variations in abundance and activity of nitrifiers in four arable cropping systems. Microbial Ecol 13: 75-87.

Busso CA, Briske DD, Olalde-Portugal V. (2001). Root traits associated with nutrient exploitation following defoliation in three coexisting perennial grasses in a semiarid savanna. Oikos 93: 332-342.

Doak BW. (1952). Some chemical changes in the nitrogenous constituents of urine when voided on pasture. J Agric Sci 42: 162-171.

Dollhopf SL, Hyun JH, Smith AC, Adams HJ, O’Brien S, Kostka JE. (2005). Quantification of ammonia-oxidizing bacteria and factors controlling nitrification in salt marsh sediments. Appl Environ Microbiol 71: 240-246.

Frank DA, Groffman PM. (1998). Ungulate vs landscape control of soil $\mathrm{C}$ and $\mathrm{N}$ processes in grasslands of Yellowstone National Park. Ecology 79: 2229-2241.

Frank DA, Groffman PM, Evans RD, Tracy BF. (2000). Ungulate stimulation of nitrogen cycling and retention in Yellowstone Park grasslands. Oecologia 123: 116-121.

Freitag TE, Prosser JI. (2003). Community structure of ammonia-oxidizing bacteria within anoxic marine sediments. Appl Env Microbiol 69: 1359-1371.

Galtier N, Gouy M, Gautier C. (1996). SEAVIEW and PHYLO_WIN: two graphic tools for sequence alignment and molecular phylogeny. CABIOS 12: 543-548.

Griffiths RI, Whiteley AS, O'Donnell AG, Bailey MJ. (2003). Physiological and community responses of established grassland bacterial populations to water stress. Appl Env Microbiol 69: 6961-6968.

Groffman PM, Rice CW, Tiedje JM. (1993). Denitrification in a tallgrass prairie landscape. Ecology 74: 855-862.

Guindon S, Gascuel O. (2003). A simple, fast, and accurate algorithm to estimate large phylogenies by maximum likelihood. Syst Biol 52: 696-704.

Hamilton EW, Frank DA. (2001). Can plants stimulate soil microbes and their own nutrient supply? Evidence from a grazing tolerant grass. Ecology 82: 2397-2402

He JZ, Shen JP, Zhang LM, Zhu YG, Zheng YM, Xu MG et al. (2007). Quantitative analyses of the abundance and composition of ammonia-oxidizing bacteria and ammonia-oxidizing archaea of a Chinese upland red soil under long-term fertilization practices. Environ Microbiol 9: 2364-2374.

Head IM, Hiorns WD, Embley TM, McCarthy AJ, Saunders JR. (1993). The phylogeny of autotrophic ammoniaoxidizing bacteria as determined by analysis of $16 \mathrm{~S}$ ribosomal-RNA gene-sequences. J Gen Microbiol 139: 1147-1153.

Hermansson A, Lindgren PE. (2001). Quantification of ammonia-oxidizing bacteria in arable soil by real-time PCR. Appl Environ Microbiol 67: 972-976.

Hesselsøe M, Brandt KK, Sorensen J. (2001). Quantification of ammonia-oxidizing bacteria in soil using microcolony technique combined with fluorescence in situ hybridization (MCFU-FISH). FEMS Microbiol Ecol 38: 87-95.

Könneke M, Bernhard AE, de la Torre JR, Walker CB, Waterbury JB, Stahl DA. (2005). Isolation of an autotrophic ammonia-oxidizing marine archaeon. Nature 437: 543-546.
Koops HP, Pommerening-Röser A. (2001). Distribution and ecophysiology of the nitrifying bacteria emphasizing cultured species. FEMS Microbiol Ecol 37: 1-9.

Kowalchuk GA, Stephen JR. (2001). Ammonia-oxidizing bacteria: a model for molecular microbial ecology. Annu Rev Microbiol 55: 485-529.

Kowalchuk GA, Stephen JR, DeBoer W, Prosser JI, Embley TM, Woldendorp JW. (1997). Analysis of ammoniaoxidizing bacteria of the beta subdivision of the class proteobacteria in coastal sand dunes by denaturing gradient gel electrophoresis and sequencing of PCRamplified 16S ribosomal DNA fragments. Appl Environ Microbiol 63: 1489-1497.

Kowalchuk GA, Stienstra AW, Hans G, Heilig J, Stephen JR, Woldendorp JW. (2000). Changes in the community structure of ammonia-oxidizing bacteria during secondary succession of calcareous grasslands. Environ Microbiol 2: 99-110.

Le Roux X, Bardy M, Loiseau P, Louault F. (2003). Stimulation of soil nitrification and denitrification by grazing in grasslands: do changes in plant species composition matter? Oecologia 137: 417-425.

Leininger S, Urich T, Schloter M, Schwark L, Qi J, Nicol GW et al. (2006). Archaea predominate among ammonia-oxidizing prokaryotes in soils. Nature 442: 806-809.

Lensi R, Mazurie S, Gourbiere F, Josserand A. (1986). Rapid determination of the nitrification potential of an acid forest soil and assessment of its variability. Soil Biol Biochem 18: 239-240.

Leriche H, Le Roux X, Gignoux J, Tuzet A, Fritz H, Abbadie L et al. (2001). Which functional processes control the short-term effect of grazing on net primary production in West African humid grasslands? Assessment by modelling. Oecologia 129: 114-124.

Luo J, Tillman RW, Ball PR. (1999). Grazing effects on denitrification in a soil under pasture during two contrasting seasons. Soil Biol Biochem 31: 903-912.

McNaughton SJ, Banyikwa FF, McNaughton MM. (1997). Promotion of the cycling of diet-enhancing nutrients by African grazers. Science 278: 1798-1800.

McNaughton SJ, Ruess RW, Seagle SW. (1988). Large mammals and process dynamics in African ecosystems. Bioscience 38: 794-800.

Mendum TA, Sockette RE, Hirsch PR. (1999). Use of molecular and isotopic techniques to monitor the response of autotrophic ammonia oxidising populations of the $\beta$-subdivisions of class Proteobacteria in arable soils to nitrogenous fertilizers. Appl Env Microbiol 65: 4155-4162.

Muyzer G, De Waal EC, Uitterlinden AG. (1993). Profiling of complex microbial populations by denaturing gradient gel electrophoresis analysis of polymerase chain reaction-amplified genes coding for $16 \mathrm{~S}$ rRNA. Appl Environ Microbiol 59: 695-700.

Nicolaisen MH, Ramsing NB. (2002). Denaturing gradient gel electrophoresis (DGGE) approaches to study the diversity of ammonia-oxidizing bacteria. J Microbiol Methods 50: 189-203.

Patra AK, Abbadie L, Clays-Josserand A, Degrange V, Grayston SJ, Guillaumaud N et al. (2006). Effects of management regime and plant species on the enzyme activity and genetic structure of $\mathrm{N}$-fixing, denitrifying and nitrifying bacterial communities in grassland soils. Environ Microbiol 8: 1005-1016.

Patra AK, Abbadie L, Clays-Josserand A, Degrange V, Grayston SJ, Loiseau P et al. (2005). Effect of grazing 
on microbial functional groups involved in soil $\mathrm{N}$ dynamics. Ecol Monogr 75: 65-80.

Perriere G, Gouy M. (1996). WWW-query: an on-line retrieval system for biological sequence banks. Biochimie 78: 364-369.

Petersen SO, Roslev P, Bol R. (2004). Dynamics of a pasture soil microbial community after deposition of cattle urine amended with $\left[{ }^{13} \mathrm{C}\right]$ urea. Appl Environ Microbiol 70: 6363-6369.

Phillips CJ, Harris D, Dollhopf SL, Gross KL, Prosser JI, Paul EA. (2000a). Effects of agronomic treatments on structure and function of ammonia-oxidizing communities. Appl Environ Microbiol 66: 5410-5418.

Phillips CJ, Paul EA, Prosser JI. (2000b). Quantitative analysis of ammonia oxidising bacteria using competitive PCR. FEMS Microbiol Ecol 32: 167-175.

Purkhold U, Pommerening-Röser A, Juretschko S, Schmid MC, Koops HP, Wagner M. (2000). Phylogeny of all recognized species of ammonia oxidizers based on comparative 16S rRNA and amoA sequence analysis: implications for molecular diversity surveys. Appl Environ Microbiol 66: 5368-5382.

Ruess RW. (1986). The role of large herbivores in nutrient cycling of tropical savannas. In: Walker BH (ed). Stress and Disturbance in Tropical Savannas. IUBS: Oxford, UK. pp 67-91.

Ruess RW, McNaughton SJ. (1987). Grazing and the dynamics of nutrient and energy regulated microbial processes in the serengeti grasslands. Oikos 49: 101-110.

Stephen JR, McCaig AE, Smith Z, Prosser JI, Embley TM. (1996). Molecular diversity of soil and marine 16S rRNA gene sequences related to beta-subgroup ammonia-oxidizing bacteria. Appl Environ Microbiol 62: 4147-4154.
Treusch AH, Leininger S, Kletzin A, Schuster SC, Klenk HP, Schleper C. (2005). Novel genes for nitrite reductase and Amo-related proteins indicate a role of uncultivated mesophilic crenarchaeota in nitrogen cycling. Environ Microbiol 7: 1985-1995.

Vitousek PM, Howarth RW. (1991). Nitrogen limitation on land and in the sea: how can it occur? Biogeochem 13: 87-115.

Wagner M, Loy A, Nogueira R, Purkhold U, Lee N, Daims H. (2002). Microbial community composition and function in wastewater treatment plants. Antonie Van Leeuwenhoek 81: 665-680.

Webster G, Embley TM, Freitag T, Smith Z, Prosser JI. (2005). Links between ammonia oxidizer species composition, functional diversity and nitrification kinetics in grassland soils. Env Microbiol 7: 676-684.

Webster G, Embley TM, Prosser JI. (2002). Grassland management regimens reduce small-scale heterogeneity and species diversity of $\beta$-proteobacterial ammonia oxidizer populations. Appl Environ Microbiol 68: 20-30.

Wertz S, Degrange V, Prosser JI, Poly F, Commeaux C, Freitag T et al. (2006). Maintenance of soil functioning following erosion of microbial diversity. Environ Microbiol 8: 2162-2169.

Wertz S, Degrange V, Prosser JI, Poly F, Commeaux C, Guillaumaud N et al. (2007). Decline of soil microbial diversity does not influence the resistance and resilience of nitrifiers and denitrifiers following a model disturbance. Environ Microbiol 9: 2211-2219.

Wheatley RE, Caul S, Crabb D, Daniell TJ, Griffiths BS, Ritz K. (2003). Microbial population dynamics related to temporal variations in nitrification in three arable fields. Eur J Soil Sci 54: 707-714.

Supplementary Information accompanies the paper on The ISME Journal website (http://www.nature.com/ismej) 